\title{
Subject-Domain Approach to the Study of Air Pollution Effects on Schoolchildren's Illness Absence
}

\author{
Jing-Shiang Hwang, ${ }^{1}$ Yi-Ju Chen, ${ }^{2}$ Jung-Der Wang, ${ }^{3,4}$ Yu-Min Lai, ${ }^{3}$ Chun-Yuh Yang,,${ }^{5}$ and Chang-Chuan Chan ${ }^{3}$
}

In this paper, the authors propose a new statistical modeling technique, the subject-domain approach, which is theoretically proven to be equivalent to the time-domain approach in detecting an association between exposure and response with time trends. The authors use an empirical data set from a school absence monitoring study conducted during the 1994-1995 school year in Taiwan to demonstrate this subject-domain approach's application to environmental epidemiologic studies. Because the subject-domain models can control the influential personal confounding factors in the models, they show greater statistical power than the traditional time-domain approaches in determining the relation between air pollution and illness absences. The authors' models found that the schoolchildren's risks of illness absence were significantly related to acute exposures to nitrogen dioxide and nitrogen oxides with a 1-day lag $(p<0.01)$ at levels below the World Health Organization's guidelines. By contrast, the authors could not detect significant associations between air pollution and schoolchildren's absenteeism using time-domain approaches. Such findings imply that the models built on subject domain may be a general solution to the problem of the ecologic fallacy, which is commonly encountered in environmental and social epidemiologic studies. Am J Epidemiol 2000;152:67-74.

air pollution; epidemiologic methods; nitrogen dioxide; statistics; time-dependent covariate; time series

Several epidemiologic studies have used time-domain methods to illustrate the effects of air pollution on hospital admissions and emergency room visits for various respiratory diseases (1-10). In these ecologic-type epidemiologic studies, daily counts of hospital admissions or emergency room visits in a geographic area are usually regressed against pollution levels measured at several fixed-site air monitoring stations in the same areas. In applications of the same time-domain methods to investigation of the relation between air pollution and illness absence, neither community-based studies nor cohort-based studies show consistent findings of air pollution effects on absence (11-16). These studies' inherent problem of the ecologic fallacy, i.e., the lack of subject-specific information in the study population, tends to bias study results toward the null. Traditional models built on time domain usually cannot include subject-

Received for publication December 28, 1998, and accepted for publication November 29, 1999.

Abbreviations: $\mathrm{PM}_{10}$, particulate matter with a diameter less than $10 \mu \mathrm{m}$; SOAP\&HIT, Study On Air Pollution and Health In Taiwan.

${ }^{1}$ Institute of Statistical Science, Academia Sinica, Taipei, Taiwan.

${ }^{2}$ Institute of Epidemiology, College of Public Health, National Taiwan University, Taipei, Taiwan.

${ }^{3}$ Institute of Industrial Hygiene and Occupational Medicine, College of Public Health, National Taiwan University, Taipei, Taiwan.

${ }^{4}$ Department of Internal Medicine, National Taiwan University Hospital, Taipei, Taiwan.

${ }^{5}$ Department of Public Health, Kaohsiung Medical College, Kaohsiung, Taiwan.

Reprint requests to Dr. Chang-Chuan Chan, College of Public Health, National Taiwan University, Room 1447, No. 1, 1st sec., Jenai Road, Taipei, Taiwan (e-mail: ccchan@ ha.mc.ntu.edu.tw). specific attributes in the models, even when such personal information is available. In the case of studies using illness absence as the outcome, we must control for each subject's personal factors, such as the individual's susceptibility factors and general environmental conditions, in order to illustrate air pollution effects on the risk of illness absence. One solution to this problem is to transform original time-series data into a subject-domain problem and make within-subject comparisons. An example is the case-crossover design for analysis of data with time trends $(17,18)$. Such a subjectdomain approach can better estimate relative risks, because individual susceptibility factors are controlled by withinsubject comparisons.

In this paper, we show that it is also valid to use the subject-domain approach to analyze time-domain problems and make between-subject comparisons. We demonstrate that time-series data can be equivalently analyzed by time-domain and subject-domain modeling approaches, theoretically as well as empirically. We further demonstrate, using data from an empirical study, that the subject-domain model is better than the time-domain model for uncovering true effects of air pollution on illness absence because person-related information can be included in the model. The data set used is from a school absence monitoring study we conducted during the 1994-1995 school year in Taiwan. The study examined 4,679 schoolchildren's illness absences attributed to respiratory diseases at six schools. It was part of an epidemiologic study on air pollution and health, the Study On Air Pollution and Health In Taiwan (SOAP\&HIT) (19). In the SOAP\&HIT, air quality data were measured from fixed-site ambient air monitoring stations, and information on personal and housing 
characteristics was obtained from a questionnaire survey. Here we describe a subject-domain approach to the estimation of acute effects of exposure to nitrogen dioxide and nitrogen oxides on the risk of illness absence from school.

\section{MATERIALS AND METHODS}

\section{Study population}

We collected the attendance records of 5,072 students aged 6-12 years from six primary schools in Taiwan during 1994-1995. The study population included 705 students from Taihsi, 954 from Keelong, 1,386 from Sanchung, 796 from Toufen, 701 from Jenwu, and 530 from Linyuan. The Taihsi school is in a rural area; the Keelong and Sanchung schools are in urban areas; and the Jenwu, Linyuan, and Toufen schools are in industrial areas where petrochemicals are produced. From these 5,072 schoolchildren, we used 4,697 students (92 percent) with absence records covering at least one school year and complete information from the questionnaire survey as our study cohort.

\section{Illness absence}

Teachers in each class of these six schools helped document the records and causes of absence for each absentee. The causes of illness absence were first screened by school nurses daily and doubly checked by trained physicians biweekly. We included only absenteeism due to respiratory diseases in our data analysis. If an individual had consecutive days of absence, only the first day was considered for that event in the analyses.

\section{Environmental data}

The hourly concentrations of six major air pollutants-particulate matter with a diameter less than $10 \mu \mathrm{m}\left(\mathrm{PM}_{10}\right)$, sulfur dioxide, nitrogen oxides, nitrogen monoxide, nitrogen dioxide, and ozone-were continuously measured by air-monitoring stations located in these six primary schools. Weather data, including temperature, wind speed and direction, and precipitation, were also measured continuously in these airmonitoring stations. The environmental data obtained from school-based monitoring stations, which are located in community centers, are generally well representative of a community's ambient air quality in Taiwan (20). Since Taiwanese schoolchildren spend most of their outdoor time at school, where classrooms are always well ventilated naturally and without air conditioning, we calculated daytime averages of environmental data from 8:00 a.m. to 6:00 p.m. in order to represent their outdoor exposures. A questionnaire survey on home characteristics (described below) was used to account for children's potential exposures to air pollutants indoors.

\section{Questionnaire}

We treated subjects' personal information from the questionnaire survey as confounding factors to be controlled in our subject-domain model. The survey was carried out at the beginning of the study. The information gathered in the questionnaire included an individual student's demographic data, personal and family history of respiratory diseases, and characteristics of the home environment. Major categories of respiratory symptoms and diseases in the questionnaire included morning cough, day or night cough, chronic cough, shortness of breath, nasal symptoms, sinusitis, wheezing or asthma, allergic rhinitis, bronchitis, pneumonia, and family history of respiratory diseases. Key indicators of home environment included a crowding index, household smoking, the presence of pets or fowl, coal stove use, gas-cooker use, incense-burning, mosquito repellent-burning, indoor plants, and home dampness.

\section{STATISTICAL METHODS}

Daily health events can generally be represented by $y_{i t}$ for students in a school. Here, $i=1, \ldots I$ index the schoolchildren and $t=1, \ldots T$ index the school days. Let $y_{i t}$ be equal to 1 when subject $i$ is absent on day $t$ and zero otherwise. Let $x_{t}$ be the area level of a pollutant measured from representative monitoring stations on lagged $h$ days. The lag ranging from 0 to 4 days was used in this paper. We may assume that $y_{i t}$ is a realization from a Bernoulli distribution with a rare rate of $p_{i t}$, which may be affected by at least two main effects of subject $i$ 's personal characteristics and the associated environmental conditions $x_{t}$.

\section{Time-domain approach}

Since illness absence is usually a rare event, it is difficult to select a proper model for testing the association between $x_{t}$ and original observed sparse $y_{i t}$ directly. However, if $x_{t}$ has an acute effect on $y_{i t}$, with the assumption of independent subjects, $x_{t}$ should also have an acute effect on daily total counts of absence, $y_{+t}=\sum_{i}^{I} y_{i t}$. Hence, the conventional time-domain approaches treat the aggregated absence counts by times, $y_{+t}$, as a conditionally independent Poisson variable when the mean total number of absentees, $p_{+t}=\sum_{i}^{I} p_{i t}$, is not too small. It is easily and widely applied to health effects studies but usually requires a large population size to have a chance to detect a significant association between $x_{t}$ and $y_{+t}$ from fitted Poisson or negative binomial models.

\section{Subject-domain approach}

One equivalent method of aggregating data by time is to aggregate the sparse $y_{i t}$ data by subject. Similarly, if $x_{t}$ have affected subject $i$ such that $y_{i t}=1$ for some $t$ 's in the study period, the average of these $x_{t}$ 's can be treated as having an acute effect on the subject's total absence in the study time period, $y_{i+}=\sum_{t}^{T} y_{i t}$. For each subject having $y_{i+}$, we define the average of these $x_{t}$ 's as the subject's level of exposure, denoted by $z_{i}=\frac{1}{\sum_{t} y_{i t}} \Sigma_{t} y_{i t} x_{i}$. When subjects have no absences during the study period, their air pollution levels 
are given a constant value, that is, the average of $x_{t}$ for all $t$ with $y_{+t}=0$. Conceivably, the original association between the area exposure index, $x_{t}$, and the time-specific population absence frequency in an area, $y_{+t}$, in the time-domain approach will be equivalent to the association between individual exposure levels, $z_{i}$, and each subject's absence frequency observed over the entire study period, $y_{i+}$, in the subject-domain approach. The theoretical proof of such equivalence is given in the Appendix.

Under this framework, we can reasonably assume $y_{i+}$ to approximate a Poisson distribution with a mean obtained by $p_{i+}=\sum_{t}^{T} p_{i t}$. Obviously, $y_{i+}$ is affected not only by the subject's air pollution levels $z_{i}$ and weather levels $w_{i}$ but also by personal/housing characteristics and other confounding factors. Here, the individual level of weather exposures for the $i$ th schoolchild, $w_{i}$, is calculated by replacing the pollutant level of $x_{t}$ in the $z_{i}$ statistic by weather measurements. Therefore, having adjusted for the influential personal variables, we expect that models built on subject domain are more powerful in detecting the association between pollutants and health outcomes.

Combining data from all students in the six schools, we propose using standard Poisson regression to model subjects' absence counts as follows:

$$
p_{k i+}=T_{k} \times \exp \left(\beta_{0}+\beta_{1} z_{k i}+\beta_{2} w_{k i}+\theta u_{k i}\right),
$$

where $p_{k i+}$ is the expected total number of absences for subject $i$ at school $k$ and $T_{k}$ is the number of school days in the study period on which data were collected at the $k$ th school. The individual level of air pollution and weather exposures for schoolchild $i$ at school $k$ are denoted by vectors $z_{k i}$ and $w_{k i}$. The vector $u_{k i}$ consists of explanatory variables including a dummy variable for area characteristics and covariates for personal characteristics.

\section{Selection of questionnaire items}

To reduce the burden of selecting proper personal variables from a large number of questionnaire items, we used classical association-testing approaches of Pearson's $\chi^{2}$ test and the generalized logit model to identify a few key factors $(21,22)$. We classified the response variable of absence counts into three categories of none ( 0 absences), low (1-3 absences), and high ( $>4$ absences), which had a natural ordering. In the same way, we classified each personal variable into appropriate categories. For example, we classified "school grade" into three categories of low (grade 1-2), medium (grade 3-4), and high (grade 5-6) and the symptom "day or night cough" into two categories of yes and no. We first applied Pearson's $\chi^{2}$ test to exclude any items that were not significantly associated with absence incidence. We then entered the items that had been screened significant into the generalized logit models to finalize the selection of personal variables. We used generalized logit models as the second step of variable selection, because the responses had a natural ordering. We reserved items that were statistically significant in more than two schools as the personal variables for the subject-domain Poisson regression model.

\section{RESULTS}

\section{Individual level of exposure}

Although the data were analyzed with different time lags, we present only the results for a 1-day lag for illustration and simplicity. As described above, individual levels of air pollution exposure were calculated according to individual students' absence records from fixed-site ambient monitoring data. For example, suppose one student has records of five absences on the dates May 1, May 2, June 4, September 27, and October 3 during the study period. Accordingly, daytime average pollutant levels measured on April 30, June 3 , September 26, and October 2 are averaged to represent this student's 1-day-lagged individual level of air pollution exposure. Exposure levels for students without any absences during the school year are calculated by averaging ambient air monitoring data on days with no absences during the study period. In total, we derive individual air pollution levels, $z_{i}$, of six air pollutants and two meteorologic parameters, $w_{i}$, for 4,697 students with a 1-day lag from the SOAP\&HIT data set.

The 1-day-lagged individual air pollution levels classified by absence counts are shown in table 1 . Among 4,697 students, 17.5 percent had at least one absence and 82.5 percent had no absences. For the 3,875 students without absences, the individual air pollution levels were 17.2 parts per billion (ppb) for sulfur dioxide, $39.3 \mathrm{ppb}$ for nitrogen oxides, 25.7 $\mathrm{ppb}$ for nitrogen dioxide, $74.3 \mu \mathrm{g} / \mathrm{m}^{3}$ for $\mathrm{PM}_{10}$, and $45.9 \mathrm{ppb}$ for ozone. For the 822 students with at least one absence, the individual air pollution levels were 17.8-19.9 ppb for sulfur dioxide, 41.2-47.1 ppb for nitrogen oxides, 27.5-31.8 ppb for nitrogen dioxide, $80.2-80.4 \mu \mathrm{g} / \mathrm{m}^{3}$ for $\mathrm{PM}_{10}$, and 46.1-46.2 ppb for ozone. Apparently, absentees' levels of pollution exposure were all greater than nonabsentees' pollution levels. Individual levels of sulfur dioxide, nitrogen oxides, and nitrogen dioxide were also positively correlated with absence frequency. Such results indicate that these three pollutants may have acute effects on illness absence. By contrast, $\mathrm{PM}_{10}$, ozone, and rainfall may have no acute effects on absence, because their individual levels did not show trends with different degrees of absence.

\section{Model comparisons}

To illustrate the improvement in statistical power for detecting pollutant effects on the risk of school absence, we make model comparisons among Poisson models built on time domain and subject domain, without and with adjustment for personal factors. All of these three models are also adjusted for weather exposures. The effects of six air pollutants on the risks of illness absence estimated by these three different modeling approaches are summarized in table 2 . The equivalence of time-domain and subject-domain modeling is affirmed from the estimated relative risks and 95 percent confidence intervals. These two models cannot detect any significant air pollution effects on absence. By contrast, 
TABLE 1. One-day-lagged individual exposures to air pollutants among 4,697 schoolchildren, by number of absences during the 1994-1995 school year, Taiwan

\begin{tabular}{ccccccccccc}
\hline \multirow{2}{*}{$\begin{array}{c}\text { No. } \\
\text { of } \\
\text { absences }\end{array}$} & $\begin{array}{c}\text { No. } \\
\text { of } \\
\text { children }\end{array}$ & $\%$ & $\begin{array}{c}\text { Sulfur } \\
\text { dioxide } \\
(\mathrm{ppb})\end{array}$ & $\begin{array}{c}\text { Nitrogen } \\
\text { oxides } \\
(\mathrm{ppb})\end{array}$ & $\begin{array}{c}\text { Nitrogen } \\
\text { dioxide } \\
(\mathrm{ppb})\end{array}$ & $\begin{array}{c}\text { Nitrogen } \\
\text { monoxide } \\
(\mathrm{ppb})\end{array}$ & $\begin{array}{c}\mathrm{PM}_{10}{ }^{*} \\
\left(\mu \mathrm{g} / \mathrm{m}^{3}\right)\end{array}$ & $\begin{array}{c}\text { Ozone } \\
(\mathrm{ppb})\end{array}$ & $\begin{array}{c}\text { Temperature } \\
\left({ }^{\circ} \mathrm{C}\right)\end{array}$ & $\begin{array}{c}\text { Rainfall } \\
(\mathrm{mm})\end{array}$ \\
\hline 0 & 3,875 & 82.50 & 17.2 & 39.3 & 25.7 & 13.6 & 74.3 & 45.9 & 24.1 & 0.20 \\
1 & 540 & 11.50 & 17.8 & 41.2 & 27.5 & 13.9 & 80.2 & 46.1 & 23.6 & 0.18 \\
2 & 163 & 3.47 & 18.0 & 42.1 & 27.8 & 14.0 & 80.2 & 46.2 & 23.5 & 0.18 \\
3 & 58 & 1.23 & 18.4 & 43.1 & 29.2 & 14.0 & 80.3 & 46.1 & 23.5 & 0.18 \\
4 & 27 & 0.58 & 18.7 & 43.9 & 29.5 & 13.9 & 80.3 & 46.1 & 23.2 & 0.19 \\
5 & 13 & 0.27 & 18.8 & 44.5 & 30.1 & 14.0 & 80.3 & 46.2 & 23.3 & 0.20 \\
6 & 6 & 0.13 & 19.2 & 44.9 & 30.6 & 13.9 & 80.4 & 46.2 & 23.2 & 0.20 \\
7 & 7 & 0.15 & 19.4 & 45.7 & 31.5 & 13.9 & 80.2 & 46.1 & 23.0 & 0.23 \\
$\geq 8$ & 8 & 0.17 & 19.9 & 47.1 & 31.8 & 14.1 & 80.4 & 46.1 & 23.0 & 0.25 \\
\hline
\end{tabular}

* $\mathrm{PM}_{10}$, particulate matter with a diameter less than $10 \mu \mathrm{m}$.

the subject-domain models with adjustment for personal factors $\left(S_{P}\right)$ illustrate significant effects on schoolchildren's illness absence by two air pollutants, nitrogen oxides and nitrogen dioxide. The $S_{P}$ models predict that relative risks of illness absence are 1.11 and 1.23 for every $10-p p b$ increase in acute exposure to nitrogen oxides and nitrogen dioxide, respectively. The $S_{P}$ models also find that relative risks are increased with narrower confidence intervals for the other four air pollutants, although their values are not statistically significant. Such empirical results demonstrate that controlling for personal factors in the $S_{P}$ models contributes significant gains to the models. Detailed effects of personal factors on illness absence are described below.

\section{Key subject attributes included in the subject-domain model}

Results from the generalized logit model suggested that school grade was a common factor affecting individual students' absence records at all six schools. Children in low grades had higher absence rates than those in high grades. The presence of family or personal respiratory symptoms/diseases was also an important factor affecting individual students' absence records at all six schools. Having a family history of respiratory diseases increased schoolchildren's absence rates in Taihsi, Keelong, and Jenwu. Illness absence also increased in Keelong, Sanchung, Linyuan, and Toufen when schoolchildren had the respiratory symptom of nasal symptoms, shortness of breath, or cough or the respiratory disease of pneumonia or asthma. By contrast, no single housing factor significantly affected students' absence rates in more than two schools. Accordingly, school grade, the child respiratory symptom of day or night cough, the child respiratory disease of wheezing or asthma, the child respiratory disease of pneumonia, and family history of respiratory diseases were five key individual confounding factors which were controlled in our subject-domain model $\left(S_{P}\right)$.

\section{Effects of various factors on illness absence}

The expected effects of air pollution and other predictors on illness absence, as estimated by the subject-domain model with a 1-day lag, are presented in table 3. Acute exposures to nitrogen oxides and nitrogen dioxide had significant effects on individual students' total absence counts $(p<$ 0.01 ), and acute exposures to sulfur dioxide had marginal effects $(p=0.08)$. By contrast, acute exposures to either $\mathrm{PM}_{10}$ or ozone had no significant effects on illness absence.

TABLE 2. Effects of air pollutants on schoolchildren's illness absences, as estimated by a 10-unit increase in pollution levels with a 1-day lag, Taiwan, 1994-1995*

\begin{tabular}{|c|c|c|c|c|c|c|}
\hline \multirow[b]{2}{*}{ Pollutant } & \multicolumn{2}{|c|}{ Time-domain approach } & \multicolumn{2}{|c|}{ Subject-domain approach } & \multicolumn{2}{|c|}{$S_{p} \dagger$} \\
\hline & $\begin{array}{l}\text { Relative } \\
\text { risk }\end{array}$ & $\begin{array}{c}95 \% \\
\text { confidence } \\
\text { interval }\end{array}$ & $\begin{array}{l}\text { Relative } \\
\text { risk }\end{array}$ & $\begin{array}{c}95 \% \\
\text { confidence } \\
\text { interval }\end{array}$ & $\begin{array}{l}\text { Relative } \\
\text { risk }\end{array}$ & $\begin{array}{c}95 \% \\
\text { confidence } \\
\text { interval }\end{array}$ \\
\hline Nitrogen oxides (10 ppb) & 1.08 & $0.98,1.19$ & 1.09 & $0.98,1.20$ & 1.11 & $1.03,1.19$ \\
\hline Nitrogen dioxide (10 ppb) & 1.14 & $0.97,1.35$ & 1.16 & $0.98,1.38$ & 1.23 & $1.07,1.41$ \\
\hline Sulfur dioxide (10 ppb) & 1.02 & $0.99,1.06$ & 1.03 & $0.99,1.08$ & 1.04 & $1.00,1.09$ \\
\hline $\mathrm{PM}_{10} \ddagger\left(10 \mu \mathrm{g} / \mathrm{m}^{3}\right)$ & 1.00 & $0.99,1.02$ & 1.01 & $0.99,1.03$ & 1.01 & $0.99,1.02$ \\
\hline Ozone (10 ppb) & 0.94 & $0.76,1.15$ & 0.95 & $0.80,1.12$ & 0.96 & $0.85,1.09$ \\
\hline Nitrogen monoxide (10 ppb) & 1.01 & $1.00,1.01$ & 1.01 & $1.00,1.01$ & 1.01 & $1.00,1.02$ \\
\hline
\end{tabular}

* Data were also adjusted for weather variables.

† Subject-domain approach with adjustment for personal data.

$\ddagger \mathrm{PM}_{10}$, particulate matter with a diameter less than $10 \mu \mathrm{m}$. 
TABLE 3. Effects of air pollution on schoolchildren's illness absences (relative risk), as estimated by subject-domain models including personal factors, Taiwan, 1994-1995

\begin{tabular}{|c|c|c|c|c|c|c|}
\hline \multirow[b]{2}{*}{ Variable } & \multicolumn{6}{|c|}{ Pollutant level (lagged 1 day) } \\
\hline & $\begin{array}{c}\text { Sulfur } \\
\text { dioxide } \\
\text { (ppb) }\end{array}$ & $\begin{array}{l}\text { Nitrogen } \\
\text { oxides } \\
(p p b)\end{array}$ & $\begin{array}{c}\text { Nitrogen } \\
\text { dioxide } \\
\text { (ppb) }\end{array}$ & $\begin{array}{c}\text { Nitrogen } \\
\text { monoxide } \\
(p p b)\end{array}$ & $\begin{array}{c}\mathrm{PM}_{10} \ddagger \\
\left(\mu \mathrm{g} / \mathrm{m}^{3}\right)\end{array}$ & $\begin{array}{c}\text { Ozone } \\
\text { (ppb) }\end{array}$ \\
\hline \multicolumn{7}{|l|}{ Pollution } \\
\hline Pollutant +10 units & $1.04 *$ & $1.11 \dagger$ & $1.23 \dagger$ & 1.01 & 1.01 & 0.96 \\
\hline \multicolumn{7}{|l|}{ Community§ } \\
\hline Keelong & $0.79 \dagger$ & 0.92 & 0.97 & 0.89 & $0.77 \dagger$ & $0.62 \dagger$ \\
\hline Sanchung & $0.82 \dagger$ & 0.85 & 0.74 & 0.74 & $0.75 \dagger$ & $0.59 \dagger$ \\
\hline Jenwu & $1.76 \dagger$ & $1.77 \dagger$ & $1.78 \dagger$ & $1.57 \dagger$ & 1.79† & $1.17 \dagger$ \\
\hline Linyuan & $1.66 \dagger$ & $1.72 \dagger$ & $1.81 \dagger$ & $1.54 \dagger$ & $1.58 \dagger$ & $1.15 \dagger$ \\
\hline Toufen & $0.42 \dagger$ & $0.43 \dagger$ & $0.39+$ & $0.57 \dagger$ & 0.88 & $0.75^{*}$ \\
\hline \multicolumn{7}{|l|}{ School gradeף } \\
\hline Medium (3-4) & $0.79 \dagger$ & $0.80 \dagger$ & $0.80 \dagger$ & $0.80 \dagger$ & $0.79 \dagger$ & $0.79 \dagger$ \\
\hline High $(5-6)$ & $0.57 \dagger$ & $0.57 \dagger$ & $0.57 \dagger$ & $0.57 \dagger$ & $0.56 \dagger$ & $0.57 \dagger$ \\
\hline \multicolumn{7}{|l|}{ Personal characteristics\# } \\
\hline Cough & $1.28 \dagger$ & $1.28 \dagger$ & $1.29 \dagger$ & $1.29 \dagger$ & $1.27 \dagger$ & 1.29† \\
\hline Family history** & $1.56 \dagger$ & $1.53 \dagger$ & $1.51 \dagger$ & $1.54 \dagger$ & $1.51 \dagger$ & 1.53† \\
\hline Pneumonia & 1.15 & 1.14 & 1.16 & 1.13 & 1.17 & 1.14 \\
\hline Wheezing or asthma & 1.14 & 1.15 & 1.15 & 1.14 & 1.14 & 1.14 \\
\hline \multicolumn{7}{|l|}{ Weather } \\
\hline Temperature $-3^{\circ} \mathrm{C}$ & $1.71 \dagger$ & 1.66† & $1.63 \dagger$ & $1.71 \dagger$ & $1.71 \dagger$ & $1.76 \dagger$ \\
\hline Rainfall (mm) & 0.81 & 0.77 & 0.77 & 0.75 & 0.77 & 0.74 \\
\hline \multicolumn{7}{|c|}{$\begin{array}{l}\text { * Significant at } p<0.10 \text { (after correction by the square root of } \chi^{2} / \mathrm{df}(\mathrm{df}=4,682) \text { for overdispersion). } \\
\dagger \text { Significant at } p<0.01 \text { (after correction by the square root of } \chi^{2} / \mathrm{df}(\mathrm{df}=4,682) \text { for overdispersion). } \\
\text { ‡ PM }{ }_{10} \text {, particulate matter with a diameter less than } 10 \mu \mathrm{m} . \\
\S \text { Reference group: Taihsi. } \\
\text { П Reference group: low (1-2). } \\
\text { \# Reference group: responses of "no". } \\
\text { ** Family history of respiratory diseases. }\end{array}$} \\
\hline
\end{tabular}

In addition to air pollution effects on absence, the subjectdomain model also detected other factors associated with schoolchildren's illness absence: temperature, community, grade, the personal symptom of day or night cough, and family history of respiratory diseases. Illness absence increased as the ambient temperature decreased. Apparently, there was also a community effect on absence after the air pollution effects of nitrogen dioxide and nitrogen oxides, weather, and other factors were adjusted for in the subject- domain model. Since the data had been adjusted for relatively worse weather conditions, the relative risks of absence for the two northern urban schools in Keelong and Sanchung were slightly lower than those for the rural Taihsi school. Compared with the rural school in Taihsi, illness absences were significantly higher in the schools in Jenwu and Linyuan but significantly lower in the school in Toufen. As table 4 shows, mean daily absence rates were 1.0 percent per thousand in Taihsi, 1.5 percent per thousand in Jenwu,

TABLE 4. Median daily air pollution and weather levels and mean daily absence rates of six schools in Taiwan during the 1994-1995 school year

\begin{tabular}{|c|c|c|c|c|c|c|c|c|c|}
\hline School & $\begin{array}{l}\text { Sulfur } \\
\text { dioxide } \\
\text { (ppb) }\end{array}$ & $\begin{array}{c}\text { Ozone } \\
\text { (ppb) }\end{array}$ & $\begin{array}{l}\mathrm{PM}_{10} * \\
\left(\mu \mathrm{g} / \mathrm{m}^{3}\right)\end{array}$ & $\begin{array}{c}\text { Nitrogen } \\
\text { oxides } \\
\text { (ppb) }\end{array}$ & $\begin{array}{l}\text { Nitrogen } \\
\text { monoxide } \\
(p p b)\end{array}$ & $\begin{array}{l}\text { Nitrogen } \\
\text { dioxide } \\
\text { (ppb) }\end{array}$ & $\begin{array}{l}\text { Temperature } \\
\left({ }^{\circ} \mathrm{C}\right)\end{array}$ & $\begin{array}{l}\text { Rainfall } \\
\text { (mm) }\end{array}$ & $\begin{array}{c}\text { Absence } \\
\text { rate } \\
(\% \circ \dagger)\end{array}$ \\
\hline Sanchung & 7.5 & 35.5 & 61.4 & 46.6 & 13.5 & 32.0 & 21.8 & 5.45 & 1.4 \\
\hline Toufen & 16.7 & 52.6 & 59.1 & 23.5 & 3.6 & 19.0 & 20.7 & 2.69 & 0.6 \\
\hline Tainsi & 4.2 & 54.2 & 74.3 & 9.6 & 0.7 & 8.5 & 22.6 & 1.96 & 1.0 \\
\hline Linyuan & 15.6 & 65.6 & 127.8 & 30.1 & 5.0 & 23.1 & 23.6 & 0.94 & 1.9 \\
\hline
\end{tabular}

* $\mathrm{PM}_{10}$, particulate matter with a diameter less than $10 \mu \mathrm{m}$.

† Percent per thousand. 
and 1.9 percent per thousand in Linyuan. Overall, schoolchildren in the Linyuan and Jenwu southern petrochemical areas took 1.5-1.9 times more sick leave than children in the rural Taihsi area. Differences in general environmental conditions, nutritional situations, and social and cultural status among communities are some possible explanations for the community effect on absence.

As table 4 shows, the yearlong measurements of ambient air quality indicate that air pollution is significantly worse in Linyuan and Jenwu than in Taihsi, while weather conditions are better in Linyuan and Jenwu. Among six air pollutants, the levels of $\mathrm{PM}_{10}$ and ozone in the schools of Jenwu and Linyuan are above current air quality guidelines. Although the concentrations of nitrogen oxides and nitrogen dioxide are still below the air quality guidelines, the air pollution levels are relatively higher in Jenwu, Linyuan, and Toufen in comparison with Taihsi. Relatively higher sulfur dioxide concentrations are also found in the three schools in Linyuan, Jenwu, and Toufen in comparison with the school in Taihsi. Therefore, schoolchildren's chronic exposure to relatively higher air pollution levels may result in higher rates of illness absence in Linyuan and Jenwu. However, the community effects on the low absence rate in Toufen, 0.6 percent per thousand, may be attributable to the residents' ethnicity rather than environmental conditions in Toufen. Although Toufen is located in a petrochemical area, its air pollution level is moderate in comparison with Linyuan and Jenwu. By contrast, the Toufen school is in a township populated mostly by persons of Hakka ethnicity, and schoolchildren in Toufen may take fewer sick days than expected because of the Hakka's renowned diligence in attending school.

\section{DISCUSSION}

The subject-domain approach proposed in this paper has the advantage of including subject-related information in the model, which can largely reduce the confounding effects seen in the traditional time-domain model. Therefore, the subject-domain model can significantly increase statistical power for detecting associations between exposures and effects in environmental epidemiologic studies. To illustrate the equivalence of statistical analysis between time-domain and subject-domain approaches with the same environmental data, we used only pollutant, weather, and area characteristic factors in the time-domain model in this paper. The residuals from the fitted time-domain models showed no patterns of day-of-week or other long term trends, except for minor autocorrelation in our data. Our subject-domain approach ignored the time-dependent structure within each subject's absence records. We believe that it has little effect on the inference, because a subject's autocorrelated absence records are usually a reflection of personal factors, which are treated as potential confounders and were included in our models.

For most air pollution and mortality studies, we usually find substantial seasonal fluctuations and long term trends in mortality data that cannot be fully explained by either air pollution or meteorology. Such trends and seasonality can be modeled by the nonparametric function fitting method in the time-domain framework. For a study on air pollution and hospital admission, we can also easily solve the day-ofweek problem by simply adding terms for dummy variables in the time-domain approach. Therefore, our subject-domain model may suffer a loss of some statistical power in such applications because of its lack of control for seasonality and day-of-week patterns. However, the limitations might be removed by building time-dependent exposure patterns in the subject-domain models. For example, we can redefine a subject's exposure level by using the observed time pattern to weight the environmental data before weighting across the subject's absence records. Another possible solution would be to identify significant trends and patterns in health outcome series first, and remove them before constructing the subject-domain models.

Apparently, using the subject-domain approach to analyze the time $\times$ subject matrix of our data set not only detects the associations between response (illness absence) and predictors (air pollution) but also identifies several personal factors influencing illness, which the time-series approach is unable to recognize. Such findings imply that the subjectdomain model may be a general solution to the problem of the ecologic fallacy, which is commonly encountered in environmental and social epidemiologic studies. One immediate application of this finding would be to use the subjectdomain approach to reanalyze data from previous studies on air pollution and health, especially when informative personal data are available in the databases.

Although Navidi's (18) bidirectional case-crossover design is also a subject-domain approach, he considers only cases in the logistic model. By contrast, our subject-domain approach used all subjects, i.e., cases and noncases, in the Poisson model. With less than 17 percent of our study population ever absent, we expect that the statistical gain from our approach is more significant than that from the crossover design, through the inclusion of all noncases' information in our study. Furthermore, the computations in our standard Poisson models are much more straightforward than the estimation procedures in Navidi's models.

We argue that the subject-domain model has no greater limitation than the conventional time-series approach in the interpretation of associations between air pollution and absenteeism. In the time-domain approach, we use air pollution levels measured at specific fixed monitoring sites as acute exposure proxies for all schoolchildren on a particular day. In the subject-domain model, we use the average of absence-related air pollution levels measured at fixed monitoring sites to represent an individual's acute exposures. In fact, personal exposures to air pollutants are not actually measured directly for individual schoolchildren in either our subject-domain model or the conventional time-domain approach.

We detected the same air pollution effects of nitrogen dioxide and nitrogen oxides on illness absence in the SOAP\&HIT data set when we used daytime as well as daily average concentrations with 0 - to 4-day lags as levels of exposure. Such findings are consistent with the results of other epidemiologic studies, which also report significant associations between nitrogen oxide-linked pollution and 
health effects at levels below World Health Organization guidelines, which are $80 \mathrm{ppb}$ for 24-hour average levels and $150 \mathrm{ppb}$ for 1-hour average levels (23-26). Accordingly, we recommend that more studies be conducted to investigate the biologic plausibility of an effect of nitrogen oxide toxicity on the respiratory system.

\section{ACKNOWLEDGMENTS}

The research described in this article was conducted through the sponsorship of contracts awarded by the National Research Council, the Executive Yuan, Taiwan (NSC-84-2621-p-002-018, NSC-84-2621-p-002-024, NSC85-2621-p-002-008, and NSC-85-2621-p-002-024).

The authors acknowledge the technical support of the Taiwan Environmental Protection Agency in the measurement of air pollution.

\section{REFERENCES}

1. Walters S, Phupinyokul M, Ayres J. Hospital admission rates for asthma and respiratory disease in the West Midlands: their relationship to air pollution levels. Thorax 1995;50:948-54.

2. Ponka A. Asthma and low level air pollution in Helsinki. Arch Environ Health 1991;46:262-70.

3. Ponka A, Virtanen M. Asthma and ambient air pollution in Helsinki. J Epidemiol Community Health 1996;50(suppl 1): S59-62.

4. Castellsague J, Sunyer J, Saez M, et al. Short-term association between air pollution and emergency room visits for asthma in Barcelona. Thorax 1995;50:1051-6.

5. Anderson HR, Limb ES, Bland JM, et al. Health effects of an air pollution episode in London, December 1991. Thorax 1995;50:1188-93.

6. Schwartz J, Slater D, Larson TV, et al. Particulate air pollution and hospital emergency room visits for asthma in Seattle. Am Rev Respir Dis 1993;147:826-31.

7. Bates DV, Baker-Anderson M, Sizto R. Asthma attack periodicity: a study of hospital emergency visits in Vancouver. Environ Res 1990;51:51-70.

8. Bates DV, Sizto R. Air pollution and hospital admissions in
Southern Ontario: the acid summer haze effect. Environ Res 1987;43:317-31.

9. Thurston G, Ito K, Hayes CG, et al. Respiratory hospital admissions and summertime haze air pollution in Toronto, Ontario: consideration of the role of acid aerosols. Environ Res 1994;65:271-90.

10. Sunyer J, Anto JM, Murillo C, et al. Effects of urban air pollution on emergency room admissions for chronic obstructive pulmonary disease. Am J Epidemiol 1991;134:277-86.

11. Romieu I, Lugo MC, Velasco SR, et al. Air pollution and school absenteeism among children in Mexico City. Am J Epidemiol 1992;136:1524-31.

12. Moll Van Charante AW, Mulder PG. Effects of smog on absenteeism in forestry workers. Arch Environ Health 1996;51:34-41.

13. Ferris BG. Effect of air pollution on school absences and differences in lung function in first and second graders in Berlin, New Hampshire, January 1966 to June 1967. Am Rev Respir Dis 1970;102:591-606.

14. Verma MP, Schilling FJ, Becker WH. Epidemiological study of illness absences in relation to air pollution. Arch Environ Health 1969;18:536-43.

15. Wayne WS, Wehrle PF. Oxidant air pollution and school absenteeism. Arch Environ Health 1969;19:315-22.

16. Ponka A. Absenteeism and respiratory disease among children and adults in Helsinki in relation to low-level air pollution and temperature. Environ Res 1990;52:34-46.

17. Maclure M. The case-crossover design: a method for studying transient effects on the risk of acute events. Am J Epidemiol 1991;133:144-53.

18. Navidi W. Bidirectional case-crossover designs for exposures with time trends. Biometrics 1998;54:596-605.

19. Chen PC, Lai YM, Wang JD, et al. Adverse effect of air pollution on respiratory health of primary school children in Taiwan. Environ Health Perspect 1998;106:331-5.

20. Chan CC, Hwang JS. Site representativeness of urban air monitoring stations. J Air Waste Manag Assoc 1996;46:755-60.

21. Agresti A. An introduction to categorical data analysis. New York, NY: John Wiley and Sons, Inc, 1996.

22. Agresti A. Categorical data analysis. New York, NY: John Wiley and Sons, Inc, 1994.

23. Schwartz J, Zeger S. Passive smoking, air pollution, and acute respiratory symptoms in a diary study of student nurses. Am Rev Respir Dis 1990;141:62-7.

24. Lebowitz MD, Collins L, Holberg CJ. Time series analyses of respiratory responses to indoor and outdoor environmental phenomena. Environ Res 1987;43:332-41.

25. Rutishauser M, Ackermann U, Braun C, et al. Significant association between outdoor $\mathrm{NO}_{2}$ and respiratory symptoms in preschool children. Lung 1990;168(suppl):347-52.

26. Braun-Fahrlander C, Ackermann-Liebrich U, Schwartz J, et al. Air pollution and respiratory symptoms in preschool children. Am Rev Respir Dis 1992;145:42-7.

\section{APPENDIX}

\section{Proof of Equivalence between the Time-Domain and Subject-Domain Approaches}

Following the notation defined in the text, the daily illness absence counts can also be decomposed as $y_{+t}=n_{t}^{(1)}+\cdots+n_{t}^{(m)}$, for some $m$ far less than $I$. Here, $n_{t}^{(j)}$ is the number of subjects who are absent on day $t$ and have a total count of illness absences $j$ in a school during the study period. Empirically, we have $n_{t}^{(j-1)} \geq n_{t}^{(j)}$ for $2 \leq j \leq m$. The set of whole population indices can be decomposed into a union of disjoint subsets, $B^{(j)}, 0 \leq j \leq m$, which consists of subject indices whose total counts of illness absence are exactly $j$ in the study period. The subject's expected mean individual air pollution levels, whose total absence count is $j$, could be estimated by the average $Z_{(j)}=\frac{1}{\# B^{(j)}} \sum_{i \in B^{(j)}} z_{i}$ for $j>0$. For those with no absences, i.e., $j=0$, the expected mean individual air pollution level is estimated by $Z_{(0)}=\frac{1}{k} \sum_{t: y_{+}=0} x_{t}$, where $k$ is the number of days having $y_{+t}=0$. Therefore, a positive association of $x_{t}$ and $y_{+t}$ implies $Z_{(j)}>Z_{(j-1)}$ for $j \geq 1$ and vice versa. 
In fact, $Z_{(j)}$ can be further rewritten as $Z_{(j)}=\frac{1}{\sum_{t} n_{t}^{(j)}} \sum_{t} n_{t}^{(j)} x_{t}$, a weighted average of $x_{t}$ for $j \geq 1$. Note that $Z_{(0)}$ is an equally weighted average of these $x_{t}$ with $y_{+t}=0$. If we let $n_{t}^{(0)}=\# B^{(0)}$ when $y_{+t}=0$ and $n_{t}^{(0)}=0$ when $y_{+t}>0$, we can rewrite $Z_{(0)}$ in the same form, $\frac{1}{\sum_{t} n_{t}^{(0)}} \sum_{t} n_{t}^{(0)} x_{t}$. Therefore, we will show that $Z_{(j)}>Z_{(j-1)}$ for $j \geq 1$ when $x_{t}$ and $y_{+t}$ are positively associated and vice versa. That is, we need to show that the weights $\frac{n_{t}^{(j)}}{\sum_{s} n_{s}^{(j)}}>\frac{n_{t}^{(j-1)}}{\sum_{s} n_{s}^{(j-1)}}$ when $x_{t}$ is large and $\frac{n_{t}^{(j)}}{\sum_{s} n_{s}^{(j)}} \leq \frac{n_{t}^{(j-1)}}{\sum_{s} n_{s}^{(j-1)}}$ when
$x_{t}$ relatively small. In the simple case of $j=1$, we have either $\frac{n_{t}^{(1)}}{\sum_{s} n_{s}^{(1)}}>0$ and $n_{t}^{(0)}=0$ for large $x_{t}$ or $n_{t}^{(1)}=0$ and $\frac{n_{t}^{(0)}}{\sum_{s} n_{s}^{(0)}}=\frac{1}{k}$ for smaller $x_{t}$ values; the truth of the equivalence statement is therefore obvious. For the case of $j \geq 2$, we give detailed arguments below.

In practical application, $n_{t}^{(j-1)}$ tends to be greater than $n_{t}^{(j)}$. Meanwhile, when $x_{t}$ is large and so is the associated $y_{+t}$, with the assumption of a positive association, then both $n_{t}^{(j-1)}$ and $n_{t}^{(j)}$ will be greater than zero. We may add one more assumption that there is a $q^{(j)}$ between 0 and 1 , such that $n_{t}^{(j)}$ is approximately equal to $q^{(j)} n_{t}^{(j-1)}$. Let $C_{1}$ be the set of time indices having both $n_{t}^{(j-1)}$ and $n_{t}^{(j)}$ greater than zero. Those time indices with $n_{t}^{(j-1)}>0$ and $n_{t}^{(j)}=0$ are grouped to $C_{2}$. This may happen when $y_{+t}$ is not large enough, i.e., when a relatively small $x_{t}$ is observed. Hence, we complete the argument with the following two statements.

$$
n_{t}^{(j)}>0 \Leftrightarrow \frac{n_{t}^{(j)}}{\sum_{s=1}^{T} n_{s}^{(j)}} \approx \frac{q^{(j)} n_{t}^{(j-1)}}{\sum_{s \in C_{1}} q^{(j)} n_{s}^{(j-1)}}=\frac{n_{t}^{(j-1)}}{\sum_{s \in C_{1}} n_{s}^{(j-1)}}>\frac{n_{t}^{(j-1)}}{\sum_{s \in C_{1} \cup C_{2}} n_{s}^{(j-1)}}=\frac{n_{t}^{(j-1)}}{\sum_{s=1}^{T} n_{s}^{(j-1)}}
$$

and

$$
n_{t}^{(j)}=0 \text { and } n_{t}^{(j-1)}>0 \text { for some } t \Leftrightarrow \frac{n_{t}^{(j)}}{\sum_{s=1}^{T} n_{s}^{(j)}}=0<\frac{n_{t}^{(j-1)}}{\sum_{s=1}^{T} n_{s}^{(j-1)}}
$$

